\title{
EXPOSIÇÃO DE LONGA DURAÇÃO DO PANTEÃO DA PÁTRIA, BRASÍLIA: SỦA RELAÇÃO COM O PÚBLICO (2015)
}

\section{EXPOSICIÓN DE LARGA DURACIÓN DEL PANTEÃO DE LA PATRIA, BRASILIA: SU RELACIÓN CON EL PÚBLICO (2015)}

\author{
Verônica Bemvenuto de Abreu e Silva* \\ Ana Lúcia de Abreu Gomes**
}

\begin{abstract}
Resumo
Introdução: Este trabalho é resultado da pesquisa de público realizada em setembro de 2015 no Museu do Panteão da Pátria, localizado na Praça dos Três Poderes, em Brasília, Distrito Federal. O museu possui um discurso bem definido e é considerado um lugar político.
\end{abstract}

Objetivo deste estudo foi analisar a relação do público com aquele espaço, verificar se as pessoas se sentem representadas com o discurso da exposição, identificar os processos que levaram à construção do espaço e fazer uma análise de como os objetivos do Museu são compreendidos pelos visitantes.

Metodologia: Este estudo foi classificado como um estudo de recepção voltado para o visitante espontâneo da exposição. Primeiramente foi feita uma contextualização da história do Panteão, foram coletados dados acerca do Museu e de seu acervo a fim de compreender mais a fundo o que motivou sua criação e qual discurso ele quer transmitir ao visitante. Em um segundo momento, por meio de aplicação de questionários foi feita a identificação de qual era o publico visitante do museu e se os visitantes se identificam ou não com aquele espaço. As informações coletadas foram sistematizadas no programa SPSS.

Resultados: Foi identificado que a maioria dos entrevistados saiu com uma impressão positiva do museu por ele falar da vida de Tancredo Neves e ressaltar um sentimento patriota, mas foi uma minoria dos visitantes que se identificou com os chamados heróis nacionais que o museu apresenta. Os visitantes ainda sentem falta de elementos mais representativos da pluralidade da sociedade no espaço.

Conclusões: Apesar da população ainda sentir necessidade de espaços como o Panteão, deve-se deixar claro que o museu é um espaço para discussões e diálogos, e não para simplesmente apresentar uma história cristalizada e sem questionamentos.

Palavras-chave: Panteão da Pátria. Estudos de público. Representação.

*Graduada em Museologia. E-mail: veronicareginadeabreu@hotmail.com

${ }^{* *}$ Doutora em História Cultural. Professora da Universidade de Brasília. E-mail: veronicareginadeabreu@hotmail.com 


\section{INTRODUÇÃO}

O Panteão da Pátria e da Liberdade Tancredo Neves encontra-se na Praça dos Três Poderes e é obra do arquiteto Oscar Niemeyer. Sua forma se assemelha a uma pomba, simbolizando a liberdade e democracia. Nas palavras do arquiteto, a forma do prédio tem a intenção de "enriquecer como um pássaro branco a Praça dos Três Poderes." (NIEMEYER, 1998. Apud MUSEU DO PANTEÃO DA PÁTRIA. [201_]. Pg.5).

Ao lado do monumento há uma pira de concreto e em seu topo uma tocha, denominada Pira da Liberdade que fica acesa 24 horas simbolizando a democracia em que vivemos. Essa pira foi inaugurada pelo ex-presidente José Sarney no ano de 1987, em homenagem a todos os "heróis construtores da pátria" (SARNEY, 1987).

Foi o governador do Distrito Federal José Aparecido de Oliveira quem teve a iniciativa de fundar esse museu com a intenção de homenagear o expresidente Tancredo Neves após sua morte em abril de 1985 (MUSEU DO PANTEÃO DA PÁTRIA). O Museu faz homenagem também aos heróis brasileiros. Sua construção foi patrocinada pela Fundação Bradesco e doada ao governo brasileiro durante a gestão do então presidente José Sarney. A pedra fundamental do Museu foi lançada pelo presidente francês François Mitterrand em outubro de 1985 e foi inaugurado no dia sete de setembro de 1986, em referência à Independência do Brasil.

Os "museus nacionais" começaram a surgir no final do século XVIII na França, após o advento da Revolução Francesa. Sua intenção era de valorizar a nação e criar uma identidade cultural própria (SANTOS, 1996, p. 22). Antes mesmo dessas instituições, os museus já apresentavam preocupação com seus públicos. Jean Davallon afirma que a história dos públicos de museus está intimamente ligada à história dos próprios museus e que, desde os seus primórdios, há preocupações sobre as pessoas que frequentam esses ambientes (DAVALLON, 1992). Desde os gabinetes de curiosidades houve cuidado sobre quem iria frequentar esses espaços, embora não se tenham feito pesquisas sobre 0 assunto até recentemente, tinha-se a preocupação sobre 0 

(2015)

que ou quem iria estar ali naquele lugar de sociabilização e também de registrar essas visitações (KÖTPCKE; PEREIRA. 2010).

As primeiras indicações de registro e impressões sobre os visitantes são provenientes dos museus europeus e estado-unidenses desde o final do século XIX e início do XX.

No decorrer do século XIX, o museu firmou-se como arena política, espaço de construção da memória coletiva e de formação de uma identidade nacional, de sociabilidade e de lazer ilustrado. Seus públicos eram diversos e numerosos. Curiosos, pesquisadores, educadores, filósofos e políticos registravam observações sobre as práticas de visita a tais espaços em cartas, textos literários, diários de viagem, artigos em periódicos. Além disso, existia o registro institucional, encontrado nos relatórios internos, regulamentos e recomendações. (KÖTPCKE; PEREIRA. 2010, p. 810)

Apesar de se ter ciência da importância dos públicos em um museu, essa figura até pouco tempo atrás não era levada em consideração nas decisões oficiais das instituições, essa preocupação formal com o visitante começou no início do século XX.

No Brasil, essa preocupação com o público foi vista a partir da publicação feita pela Diretoria Geral de Estatística: Primeiro Anuário Estatístico do Brasil, sobre a oferta dos museus e seus visitantes por mês e ano, de 1908 a 1912. Esse dado foi coletado pelas prestações de contas que os museus deviam aos órgãos a que eram subordinados, muito parecidos com os museus públicos do Governo do Distrito Federal nos dias de hoje, que são submetidos à Secretaria de Cultura e mandam seus livros de visitas todo mês à Secretaria para que lá se registre esse controle de visitas e todo tipo de documentação relacionado aos museus dependentes. (KÖTPCKE; PEREIRA, 2010)

Atualmente, os visitantes já são alvo de pesquisas formais em muitas instituições. Jean Davallon (1992) argumenta ainda que o visitante possua uma posição essencial dentro da evolução do museu e que muitas instituições já fazem estudos de públicos de forma sistemática e regular ${ }^{1}$. O Museu do

${ }^{1}$ Importante ressaltar que o autor estuda somente os casos norte-americanos e franceses em seu trabalho. 

(2015)

Panteão, no entanto, não desenvolve pesquisas que se proponham a avaliar de forma qualitativa as visitas que recebe e há certa carência de estudos de público nas instituições de Brasília.

É de relevância um estudo de público nesse tipo de museu porque esses memoriais e panteões têm a preocupação de lembrar à sociedade as figuras de importância na história do país. No Panteão da Pátria, os fatos e personagens ali expostos são de importância na história brasileira e partem do princípio de colaborar para a construção da identidade de uma nação.

A exposição de longa duração presente no Panteão da Pátria possui um discurso que, nas palavras de Maria Célia Santos "apresenta uma memória nacional unificadora, que procura a harmonia e escamoteia ou sublima os conflitos" (SANTOS, 1996, p. 25). Ela tem um discurso cuja intenção é que os visitantes saiam convictos de que as figuras ali apresentadas tiveram somente aquele papel cristalizado de herói e não mostra ou cita as outras faces da história, mostrando ao visitante e deixando-o acreditar que a única versão da história é a que está ali exposta, congelada e inquestionável. A pesquisa aplicada no Panteão da Pátria tem a intenção de identificar como é a relação das pessoas com o espaço expositivo.

Os objetivos do trabalho são verificar se as pessoas se sentem representadas com o discurso da exposição de longa duração do Panteão da Pátria em Brasília, e de forma mais específica, identificar os processos que levaram à construção do museu e fazer uma análise de como os objetivos do Museu são compreendidos pelos visitantes.

\section{METODOLOGIA}

A intenção na seguinte pesquisa foi fazer um estudo sobre o público do PPTN e entender como as pessoas interpretam o que está exposto naquele espaço. Foram apreendidos dois conceitos de estudos de público neste trabalho, a consideração elaborada por Sepúlveda que entende estudo de público como "todo tipo de investigação sobre os visitantes, com independência dos objetivos perseguidos na exposição" (KÖPTCKE, 2003, p.5). E o argumento feito por McManus, 
Como uma área de aplicação das ciências sociais que diz respeito ao comportamento humano e à comunicação humana em espaços museológicos. Ela consiste de enquetes junto aos visitantes, estudos de avaliação e projetos de pesquisa sobre o público de museus. (MCMANUS, 1991. Apud STUDART, 2005, p. 33).

Para pesquisas de público, há uma organização dos tipos de estudos segundo a intenção e o resultado que se quer atingir. São classificados o público potencial, o não público, o público alvo e o público efetivo, há ainda outros tipos de públicos não citados aqui. A organização dos tipos são:

Os estudos relacionando os objetivos, o alvo e as perguntas. [...]. Assim, junto ao público efetivo, tratando das práticas reais de visita, os objetivos são sintetizados em três grupos principais: as sociografias, que visam descrever o perfil e as modalidades de apropriação das instituições; os estudos de fluxo, que pretendem acompanhar a dinâmica das visitas ao longo do tempo, contabilizando quantas pessoas realizam tal prática; e os estudos de recepção, que buscam compreender as formas de apropriação e o sentido das práticas junto aos visitantes. (Octobre, 2007. Apud KÖPTCKE, 2012, p. 216).

O estudo apresentado neste trabalho é um estudo de recepção, visto que a intenção é saber o que os visitantes espontâneos do Panteão da Pátria pensam da exposição e como se apropriam da informação que é veiculada no espaço. Ao analisar a história oficial que o Panteão conta e assimilar com seus conhecimentos, opiniões e experiências já vividas o visitante sai do museu com uma opinião sobre o lugar, se sentindo identificado ou não com o discurso expográfico. É importante que o museu deixe claro seus objetivos para que o público possa se identificar com eles ou não após a visita, da mesma forma, também é importante analisar o porquê de o visitante concordar ou não com o que foi proposto pela exposição.

Primeiramente foi feita contextualização da história do Panteão, seus motivos de criação e apresentação de sua exposição. Para isso, foram feitas saídas de campo à Secretaria de Cultura, arquivo do Correio Braziliense e levantamento bibliográfico em bibliotecas e bases de dados. Em seguida foi feita a identificação de qual o público que frequenta o Museu e sua opinião sobre a exposição, essa identificação foi feita por meio de aplicação de questionário. 
Não buscamos aqui saber a percepção dos visitantes em visitas guiadas, pois nesse tipo de experiência o visitante cria opinião baseada nas experiências que o mediador proporciona ou não. Queremos saber as percepções da "prática real" da visita ao museu e a identificação do visitante com o espaço, e para isso, respondeu o questionário o público espontâneo do Museu a partir de 15 anos de idade.

Os questionários aplicados são de caráter de levantamento amostral probabilístico, esse tipo de pesquisa é definido como:

\begin{abstract}
Quando qualquer membro de uma população alvo tem uma probabilidade conhecida $(>0)$ de ser incluído na amostra. $\mathrm{O}$ objetivo de uma amostra probabilística é eliminar a subjetividade e obter uma amostra que seja imparcial e representativa da população alvo. É importante lembrar que não podemos fazer nenhuma conclusão estatística dos dados obtidos a menos que tenhamos uma amostra probabilística. (FORTE, 2007, p. 7)
\end{abstract}

Para manter o caráter cientifico do levantamento é necessário o cálculo amostral para definição de quantos questionários teriam que ser respondidos, e formulação de perguntas adequadas às respostas que se deseja alcançar. $O$ universo estudado é o público espontâneo do PPTN, a média de visitação no museu por mês é de 3.000 pessoas $^{3}$. Para descobrir quantas pessoas seriam necessárias entrevistar foi feito um cálculo estatístico.

O índice de confiança da pesquisa é de $95 \%$ com margem de erro de $5 \%$. O total de questionários respondidos e analisados é de 345 , todos de indivíduos brasileiros, com idade a partir de 15 anos de idade. A aplicação desse questionário se deu entre os dias 5 a 26 de setembro de 2015, somente aos finais de semana, pois são nos sábados e nos domingos os dias de maior visitação espontânea no Centro Cultural dos Três Poderes. Foi escolhido o mês de setembro para aplicação de questionário por esse ser um mês com datas marcantes para a história do país e se pensou que, com essa data, da

\footnotetext{
${ }^{2}$ Pesquisadora Luciana Sepúlveda, referindo a uma prática onde o visitante não participa de nenhuma mediação durante a visita (KÖTPCKE, 2007).

${ }^{3}$ Informação obtida na própria administração do museu com base nos livros de visitação.
} 
Verônica Bemvenuto da Abreu e Silva, Ana Lúcia Abreu e Gomes Exposição de longa duração do panteão da pátria, Brasília: sua relação com o público (2015)

Independência do Brasil, haveria uma reflexão mais diferenciada por parte do visitante.

O questionário era entregue ao visitante ao final da visita, como só há uma entrada no prédio ficou mais fácil de controlar os visitantes que se disponibilizavam a responder ou não os questionários. As perguntas do questionário foram pensadas com o intuito de identificar quais são as pessoas que visitam esse espaço e foram formuladas com base em bibliografias sobre estudos de público em museu e na idéia sobre quais variáveis básicas que poderiam influenciar a opinião do visitante ao passear pelo espaço. Variáveis que não pudemos controlar facilmente e que não interfeririam fortemente na pesquisa foram descartadas. As perguntas com caráter de identificação do visitante foram fechadas, com múltipla escolha (exceto a questão de número 4 , que diz respeito sobre a Unidade da Federação de onde vem o visitante), e as perguntas sobre a exposição foram abertas, dando espaço para o visitante expressar suas opiniões sobre o espaço livremente. Após a aplicação do questionário, as perguntas subjetivas foram separadas em categorias de respostas mais frequentes.

As informações coletadas durante a aplicação de questionários foram organizadas e sistematizadas no programa SPSS. A aplicação de questionários foi observada e essas ressalvas foram anotadas em um caderno de campo.

\section{O PANTEÃO DA PÁTRIA TANCREDO NEVES}

O Panteão da Pátria tem uma narrativa bastante influenciada no pensamento de Gustavo Barroso ${ }^{4}$ por fornecerem seu espaço expositivo uma história oficial e elementos de preservação para uma nação pronta e inquestionável.

\footnotetext{
${ }^{4}$ Para Barroso, conservar ou preservar os objetos está intimamente relacionado a uma função, a de "fazer amar a pátria", sendo assim a responsabilidade do museu é "fazer brotar nos indivíduos um sentimento nacional", (BARROSO, apud SANTOS, 1996, p. 24).
} 
O PPTN, assim como todo museu, tem uma capacidade de influência grande, sendo assim, deve ser tratado como instrumento de poder. Essas instituições têm peso sobre o processo de construção identitária dos indivíduos. Os objetos ali dispostos não foram escolhidos ao acaso, e todo o discurso do espaço expositivo está fazendo uma ressignificação do passado. Toda exposição tem uma intenção definida do que se quer passar, não há exposições neutras, assim como não há museus neutros (DAVALLON, 1992).

O museu é dividido em três andares, sendo dois deles para área expositiva e o terceiro, o subsolo, para assuntos administrativos. No primeiro andar, chamado Salão Vermelho, está a primeira parte da exposição, essa parte faz uma homenagem ao ex- presidente Tancredo Neves, está alocado também neste andar o Mural da Liberdade, do artista Athos Bulcão, homenageando os inconfidentes mineiros.

No segundo andar do museu, o Salão Principal, estão o Painel da Inconfidência Mineira, o Livro de Aço, o busto do almirante Joaquim Marques Lisboa, patrono da marinha de guerra no Brasil e o vitral da artista Mariane Peretti ${ }^{5}$.

A inscrição da capa do Livro de Aço diz "Aos heróis do Brasil, a pátria reconhecida", uma confirmação da eternização de seus nomes como heróis da nação. Ele possui 42 nomes inscritos atualmente e anualmente é feita uma análise de nomes a serem inscritos no livro. Para que o nome seja gravado no Livro a Câmara dos Deputados e o Senado devem aprovar por lei ${ }^{6}$.

O herói apresentado aqui não é aquele que Roberto da Matta problematiza em suas reflexões, aquele que existiria tanto na "consciência popular" quanto na "alta cultura", visto que foi uma minoria que se sentiu

\footnotetext{
${ }^{5}$ Artista Mariane Peretti é francesa, viveu e estudou em Paris até 1953, ano em que se mudou para o Brasil, lugar que vive ate hoje e desenvolve seus trabalhos, principalmente no Nordeste. (MUSEU DO PANTEAO, [201].P. 45)

${ }^{6}$ Critérios básicos para que alguém possa ser considerado herói brasileiro estão disponíveis no site da Câmara dos deputados.

Lei no 11.597 de 29 de novembro de 2007.

${ }^{7}$ "[...] cabe observar que os nossos três heróis (o Caxias, o malandro e o renunciador) existem tanto na chamada "consciência popular" quanto no que rotineiramente se denomina "alta cultura"." (DA MATTA, 1997, p. 285)
} 

(2015)

identificada com os heróis apresentados no Livro de Aço. O que apresenta certa contradição, considerando que nossos deputados- escolhidos por nós para nos representar na câmara legislativa- em momento de grande decisão política, clamaram por essas pessoas que eles aprovaram para estarem em um livro de heróis da pátria.

\section{A QUESTÃO DA IDENTIDADE}

Falamos agora na atualidade não de uma identidade fixa e imutável, mas sim de uma identificação de tomada de posição, essa essência que cada um de nós teria sempre não é mais levada em consideração. Hall (2006) afirma que as identidades estão sempre em processo de formação, elas se deslocam e se cruzam de acordo com a situação e necessidade de tomar decisões que a pessoa adota. Falamos, portanto sobre posicionamento.

As identificações construídas pelas culturas nacionais, segundo Stuart Hall (2006), são mantidas por meio de comemorações, eventos, literatura, rituais cívicos, mitos fundacionais, tradições e uma série de outras manipulações simbólicas ${ }^{8}$ que agem de forma a unir essa nação.

As tradições em sua maioria são invenções recentes para ressaltar o sentimento de identificação. Já os mitos fundacionais de uma nação são as histórias da origem dessa nação. "Eles fornecem uma narrativa através da qual uma história alternativa ou uma contra narrativa, que precede as rupturas da colonização, pode ser construída" (HALL, 2006, p. 55).

Os museus seriam o espaço ideal para consolidação desses mitos e dos sentimentos de identificação, pois servem de recurso estratégico para esse fim, sendo instrumento de poder e influência para moldar o imaginário das pessoas (MENESES, 1993. p. 212). No Brasil, em alguns livros didáticos a

\footnotetext{
${ }^{8}$ Termo retirado do texto $A$ força de representação de Pierre Bourdieu, essa manipulação simbólica se utiliza, segundo o autor para determinar as representações mentais que constroem propriedades que podem ser usadas com uma dada finalidade dependendo do portador do conhecimento, portanto, o portador do conhecimento dessas manipulações simbólicas é que deteria o poder sobre elas (BOURDIEU, 1980, p. 108).
} 

(2015)

proclamação da República ainda é contada de forma fantasiosa, como se tivesse ocorrido da forma como a obra pictórica Independência ou Morte que Pedro Américo apresenta, ou ainda adotam heróis para a nação como Tiradentes, personagem erigido no fim da monarquia e início da república.

O empenho para achar um herói brasileiro surgiu com o início das discussões para o surgimento do regime republicano. Ao fim do período monárquico havia a necessidade de uma figura que representasse os princípios de liberdade que o novo regime pregava. Necessitava-se na época de símbolos e pontos de referência para uma identificação coletiva que servissem de apoio para que a república pudesse se estabelecer. Seriam esses os heróis nacionais, personalidades tão exaltadas de forma que, segundo Mircea Eliade, "as personagens desses mitos deixam de ser seres humanos e se tornam deuses ou heróis civilizadores." (ELIADE, 2001. Apud BALLAROTTI, 2009. p. 221).

No início da República houve vários candidatos a herói oficial da nação ${ }^{9}$, pessoas como Marechal Deodoro da Fonseca e Frei Caneca que estão hoje no livro de aço dos heróis nacionais partilhando esse título com o patrono cívico do nosso país. Acabou vencendo o título de herói da república a figura de Tiradentes. Ele foi e ainda é um personagem bastante controverso, exaltado tanto pelos grupos que clamaram a república e os ideais de liberdade quanto pelos ditadores que tivemos e que chegaram a transformar esse herói em patrono cívico da nação em 1965.

É importante ressaltar que o país não possui uma só cultura homogeneizada, não podemos dar unicidade à identidade nacional porque, principalmente em um país como o Brasil, de dimensões continentais, não há uma só identificação nacional, muito menos heróis nacionais padronizados para uma nação inteira.

\footnotetext{
${ }^{99}$ CARVALHO, José Murilo de. Tiradentes: Um herói para a República In: A formação das almas: O imaginário da República no Brasil. São Paulo, Companhia das Letras, 1990, pp. 5573.
} 
Já foi ressaltada aqui a importância da instituição museu na constituição do cidadão, do seu papel na construção de identidade e seu papel como mídia. Vale lembrar ainda o museu como produtor de discursos sociais e instrumento de poder (DAVALLON, 1992).

Meneses (1993) adverte ainda que os museus devam ter obrigatoriamente uma postura crítica com relação à problemática da identidade sempre, já que elas são fatores essenciais para a constituição do indivíduo. Pedro Funari e Aline Carvalho afirmam que

Não é raro encontrarmos exposições que trabalham com a premissa de uma identidade coesa e fixa atribuída a determinados grupos culturais. Todavia, é preciso destacar que a identidade não se configura como um dado estático ou inerente aos indivíduos e suas comunidades. (FUNARI e CARVALHO, 2011, p. 182)

Esses espaços, tendo noção de seu poder de influência e de tomadas políticas de decisões, precisam servir de aparatos para reflexão e questionamentos, não cabendo a eles dar certezas de fatos e identidades já prontas e cristalizadas. Os heróis e a história de uma nação precisam ter coerência e entrar em concordância com o que as pessoas dessa nação pensam.

Tabela 1: Por que as pessoas se sentem representadas ou não (categorias)

\begin{tabular}{lcc}
\hline \multicolumn{1}{c}{ Respostas categorizadas } & $\begin{array}{c}\text { Frequência } \\
\text { Absoluta }\end{array}$ & $\begin{array}{c}\text { Frequência } \\
\text { Relativa }\end{array}$ \\
\hline Não respondeu & 68 & $19,71 \%$ \\
Tancredo Neves/Patriotismo & 37 & $10,72 \%$ \\
Democracia, Liberdade e Justiça & 25 & $7,25 \%$ \\
Heróis Nacionais & 24 & $6,96 \%$ \\
História do País & 98 & $28,41 \%$ \\
Outros & 93 & $26,96 \%$ \\
Total & 345 & \\
\hline Fonte: Exposição de longa duração do panteão da pátria, brasília: Sua relação com o
\end{tabular}


Uma grande maioria das pessoas se sente representada ao visitar o PPTN. Mas, ao analisar as respostas, foi verificado que não é por todos os elementos que elas se sentem representadas, a maioria se sente representada porque aquele local fala de uma parte significativa na história do país, e não pelos personagens ali apresentados.

A análise das respostas evidencia o fato de que as pessoas não se sentem representadas pelos heróis nacionais abrigados naquele Museu, mas sim pelo fato de aquele local contar parte da história do país. Não a história completa do Brasil como confundem alguns, ou a história da criação de Brasília, como propuseram outros, mas sim uma parte significativa para o desenvolvimento do país. Elas reconhecem o papel do Museu de informar e preservar a história oficial e dão importância a isso.

Importante analisar também a relação sobre o que as pessoas destacam como sendo os elementos mais significativos da exposição e se elas se sentem representadas ou não. A grande maioria das pessoas que associou os elementos que falavam da figura de Tancredo Neves e sobre a democracia respondeu que se sentia representada, mas também, por esse mesmo motivo, a maioria disse que não se sentia representada. $O$ fato de a pessoa destacar que os elementos mais significativos da exposição eram relacionados à democracia e a Tancredo Neves nada tem a ver com o fato de ela se sentir representada ali ou não. Pode-se notar também que a relação com os heróis nacionais é mínima, tanto as pessoas que responderam sim quanto as que responderam não.

\section{RESULTADOS DA PESQUISA}

Foram entrevistadas 345 pessoas, no período que compreende os dias 5 e 26 de setembro de 2015. Essa pesquisa foi realizada somente durante os fins de semana, por serem esses os dias de maior fluxo de visitas espontâneas. Foi escolhido esse período por ser esse o mês em que é lembrada a Independência do Brasil e o aniversário de abertura do Panteão. Consideramos que tais fatos teriam maior poder de despertar uma visão mais crítica dos visitantes com relação com que vissem exposto. 
Da população entrevistada, 161 eram mulheres, 151 homens e 33 não preencheram esse campo. A faixa etária é a partir de 15 anos, sendo a maioria dessas pessoas com idade entre 15 a 30 anos e com nível superior. Pessoas de 24 estados preencheram esse questionário, sendo a maioria dessas da região Centro oeste, residentes no Distrito Federal.

Durante a aplicação de questionários, alguns pontos chamaram mais a atenção. Ao chegarem à porta do museu, muitas pessoas não sabiam o que aquele espaço era e nem se podiam visitá-lo. Houve muitas perguntas sobre se era possível entrar no museu, o que aquele espaço era e sobre o que falava.

As primeiras perguntas foram com intenção de identificar esse público visitante do museu, as perguntas foram sobre sexo, idade, nível de escolaridade e Unidade da Federação em que mora. Em seguida foram feitas as perguntas em aberto, a respeito da exposição do museu em si.

Ao analisar os questionários respondidos foi notada resistência em responder as perguntas em aberto, principalmente proveniente do público masculino. Uma média de $24 \%$ dos participantes não respondeu pelo menos uma das questões.

Percebe-se com essa pesquisa, um público majoritariamente elitizado e educado formalmente, quase $80 \%$ da população entrevistada possui nível superior. Bourdieu, em sua obra $O$ amor pela arte, afirma que "a frequência dos museus- que aumenta consideravelmente à medida que o nível de instrução é mais elevado- corresponde a um modo de ser, quase que exclusivo das classes cultas." (BOURDIEU, 2007, p. 37). Isso é observável não só nos museus europeus, mas também aqui no Brasil, visto que a grande maioria do público visitante do PPTN é de ensino superior.

É possível perceber as implicações desse alto nível de escolaridade ao observar as respostas dos questionários. Ao perguntarmos quais os elementos que a exposição quer passar ao visitante, vemos as mais variadas respostas. Não foram identificadas muitas diferenças nas respostas entre os níveis de escolaridade devido a esse grande desnível. Ao analisar as respostas dessa pergunta, essas foram separadas em cinco categorias de respostas mais frequentes. Elas foram separadas nos elementos que o visitante destacou 
Verônica Bemvenuto da Abreu e Silva, Ana Lúcia Abreu e Gomes Exposição de longa duração do panteão da pátria, Brasília: sua relação com o público (2015)

como: Tancredo Neves e democracia (TN/D), Heróis nacionais (HN) e História do país (HP), também foram categorizadas as respostas deixadas em branco (EB) e as que não se encaixavam em nenhuma das categorias acima (OC), geralmente essas respostas são associadas a objetos da exposição, aos recursos que ela utiliza e opiniões próprias sobre o espaço físico do museu.

Tabela 2: Quais elementos essa exposição quer destacar ao visitante? (Categorias)

\begin{tabular}{lcc}
\hline Respostas categorizadas & Frequência Absoluta & Frequência Relativa \\
\hline Tancredo Neves/Democracia & 170 & $49,28 \%$ \\
Heróis Nacionais & 32 & $9,28 \%$ \\
História do País & 46 & $13,33 \%$ \\
Não respondeu & 30 & $8,70 \%$ \\
Outros & 67 & $19,42 \%$ \\
\hline Total & 345 & \\
\hline Fonte: & Exposição de longa duração do panteão da pátria Brasília
\end{tabular}

Fonte: Exposição de longa duração do panteão da pátria, Brasília

Na pergunta de número seis, foi preciso separar os grupos de pessoas, se elas se sentiam representadas (Sim, não, não respondeu, não soube responder) e depois, em categorias para responder o porquê de suas respostas. Mesmo não respondendo a pergunta, muitas pessoas fizeram comentários sobre a exposição, que pela análise das respostas não foi possível identificar se era positiva ou negativa, essas pessoas entraram na categoria "não soube responder".

Tabela 3: Sendo brasileiro, você diria que se sente representado ao visitar essa exposição?

\begin{tabular}{lcc}
\hline Resposta & Frequência Absoluta & Frequência Relativa \\
\hline Sim & 238 & $68,99 \%$ \\
Não & 59 & $17,10 \%$
\end{tabular}


Verônica Bemvenuto da Abreu e Silva, Ana Lúcia Abreu e Gomes Exposição de longa duração do panteão da pátria, Brasília: sua relação com o público (2015)

\begin{tabular}{lcc} 
Não respondeu & 25 & $7,25 \%$ \\
\hline Não soube responder & 23 & $6,67 \%$ \\
\hline Total & 345 & \\
\end{tabular}

Fonte: Exposição de longa duração do panteão da pátria, Brasília:

As categorias selecionadas para responder o porquê das pessoas se sentirem representadas ou não na exposição foram sobre elementos relacionados a Tancredo Neves e patriotismo (TN/P), história do país (HP), democracia e liberdade $(D / L)$, pessoas com influência na história do país ou heróis nacionais $(\mathrm{HN})$, em branco $(\mathrm{EB})$ e outras coisas $(\mathrm{OC})$.

$\mathrm{Na}$ categoria OC é observada uma peculiaridade. Neste campo, grande parte das pessoas com até 30 anos que não se identificam com aquele espaço, argumentaram que os elementos ali apresentados não representam a cultura do país, que a história está incompleta ou que a exposição é parcial. Já as pessoas com idade a partir dos 40 anos responderam que se identificam porque a história ali contada faz parte da história deles também, que eles vivenciaram aquela parte da história e sentem que fazem parte daquilo. As pessoas com idade entre 30 e 40 anos ficaram bem divididas com relação à sua participação pessoal nessa história, mas ainda associam sua participação à memória também, como as pessoas acima de 40 anos.

As pessoas com idade a partir de 40 anos associam aquele lugar à memória do período da ditadura militar, se incluindo nessa história e fazendo referência ao primeiro andar da exposição (que conta a história de Tancredo Neves e sua relação com o período da ditadura) como a memória da ditadura militar. Por terem participado desse período, elas fazem essa associação e se sentem representadas por terem tido participação na história do país e intimidade com a figura de Tancredo Neves, como a senhora que levou as fotos dos pais lado a lado com o ex-presidente para mostrar a todos os funcionários do Museu.

As pessoas com até 40 anos fazem associação com a história, aquilo já não está mais em sua memória, eles precisam de um lugar para isso, e 
Verônica Bemvenuto da Abreu e Silva, Ana Lúcia Abreu e Gomes Exposição de longa duração do panteão da pátria, Brasília: sua relação com o público (2015)

consideram que esse período fez parte significativa da história de seu país. Sendo assim, lêem naquele "lugar de memória", a história que é compartilhada entre os residentes de um mesmo país.

Esses dois tipos de respostas estão na mesma categoria porque não são respostas suficientes para ser uma categoria própria, mas são informações significativas sobre o que foi apreendido nas visitações, o que as pessoas sentem ao sair de lá e o porquê de se sentirem representadas ou não.

Tabela 4: Sendo brasileiro, você diria que se sente representado ao visitar essa exposição?

\begin{tabular}{lcc}
\hline \multicolumn{1}{c}{ Resposta } & Frequência Absoluta & Frequência Relativa \\
\hline Sim & 238 & $68,99 \%$ \\
Não & 59 & $17,10 \%$ \\
Não respondeu & 25 & $7,25 \%$ \\
Não soube responder & 23 & $6,67 \%$ \\
Total & 345 &
\end{tabular}

Fonte: exposição de longa duração do panteão da pátria, Brasília

As categorias selecionadas para responder o porquê das pessoas se sentirem representadas ou não na exposição foram sobre elementos relacionados a Tancredo Neves e patriotismo (TN/P), história do país (HP), democracia e liberdade (D/L), pessoas com influência na história do país ou heróis nacionais $(H N)$, em branco $(E B)$ e outras coisas $(\mathrm{OC})$.

$\mathrm{Na}$ categoria OC é observada uma peculiaridade. Neste campo, grande parte das pessoas com até 30 anos que não se identificam com aquele espaço, argumentaram que os elementos ali apresentados não representam a cultura do país, que a história está incompleta ou que a exposição é parcial. Já as pessoas com idade a partir dos 40 anos responderam que se identificam porque a história ali contada faz parte da história deles também, que eles vivenciaram aquela parte da história e sentem que fazem parte daquilo. As pessoas com idade entre 30 e 40 anos ficaram bem divididas com relação à sua participação pessoal nessa história, mas ainda associam sua participação à memória também, como as pessoas acima de 40 anos.

As pessoas com idade a partir de 40 anos associam aquele lugar à memória do período da ditadura militar, se incluindo nessa história e fazendo referência ao primeiro andar da exposição (que conta a história de Tancredo Neves e sua relação com o 
Verônica Bemvenuto da Abreu e Silva, Ana Lúcia Abreu e Gomes Exposição de longa duração do panteão da pátria, Brasília: sua relação com o público (2015)

período da ditadura) como a memória da ditadura militar. Por terem participado desse período, elas fazem essa associação e se sentem representadas por terem tido participação na história do país e intimidade com a figura de Tancredo Neves, como a senhora que levou as fotos dos pais lado a lado com o ex-presidente para mostrar a todos os funcionários do Museu.

As pessoas com até 40 anos fazem associação com a história, aquilo já não está mais em sua memória, eles precisam de um lugar para isso, e consideram que esse período fez parte significativa da história de seu país. Sendo assim, lêem naquele "lugar de memória", a história que é compartilhada entre os residentes de um mesmo país.

Esses dois tipos de respostas estão na mesma categoria porque não são respostas suficientes para ser uma categoria própria, mas são informações significativas sobre o que foi apreendido nas visitações, o que as pessoas sentem ao sair de lá e o porquê de se sentirem representadas ou não.

Tabela 5: Por que as pessoas se sentem representadas ou não (categorias)

\begin{tabular}{|c|c|c|}
\hline Respostas categorizadas & Frequência Absoluta & Frequência Relativa \\
\hline Não respondeu & 68 & $19,71 \%$ \\
\hline Tancredo Neves/Patriotismo & 37 & $10,72 \%$ \\
\hline Democracia, Liberdade e Justiça & 25 & $7,25 \%$ \\
\hline Heróis Nacionais & 24 & $6,96 \%$ \\
\hline História do País & 98 & $28,41 \%$ \\
\hline Outros & 93 & $26,96 \%$ \\
\hline Total & 345 & \\
\hline
\end{tabular}

Fonte: exposição de longa duração do panteão da pátria, Brasília

Tabela 6: Relação entre sentir-se representada pela exposição e motivos: Sendo brasileiro, você diria que se sente representado ao visitar essa exposição

\begin{tabular}{lccccc}
\hline $\begin{array}{l}\text { Motivos categorizados } \\
\text { para se sentir } \\
\text { representado ou não }\end{array}$ & Sim & Não & $\begin{array}{l}\text { Não } \\
\text { respondeu }\end{array}$ & $\begin{array}{l}\text { Não soube } \\
\text { responder }\end{array}$ & Total \\
\hline Não respondeu & 30 & 10 & 25 & 3 & 68 \\
$\begin{array}{l}\text { Tancredo } \\
\text { Neves/Patriotismo }\end{array}$ & 24 & 11 & 0 & 2 & 37 \\
$\begin{array}{l}\text { Democracia, Liberdade } \\
\text { e Justiça }\end{array}$ & 21 & 2 & 0 & 2 & 25 \\
\hline
\end{tabular}


Verônica Bemvenuto da Abreu e Silva, Ana Lúcia Abreu e Gomes Exposição de longa duração do panteão da pátria, Brasília: sua relação com o público (2015)

\begin{tabular}{lccccc} 
Heróis Nacionais & 13 & 10 & 0 & 1 & 24 \\
História do País & 92 & 3 & 0 & 3 & 98 \\
Outros & 58 & 23 & 0 & 12 & 93 \\
Total & $\mathbf{2 3 8}$ & $\mathbf{5 9}$ & $\mathbf{2 5}$ & $\mathbf{2 3}$ & 345 \\
\hline
\end{tabular}

Fonte: Exposição de longa duração do panteão da pátria, Brasília

Uma grande maioria das pessoas se sente representada ao visitar o PPTN. Mas, ao analisar as respostas, foi verificado que não é por todos os elementos que elas se sentem representadas, a maioria se sente representada porque aquele local fala de uma parte significativa na história do país, e não pelos personagens ali apresentados.

A análise das respostas evidencia o fato de que as pessoas não se sentem representadas pelos heróis nacionais abrigados naquele Museu, mas sim pelo fato de aquele local contar parte da história do país. Não a história completa do Brasil como confundem alguns, ou a história da criação de Brasília, como propuseram outros, mas sim uma parte significativa para 0 desenvolvimento do país. Elas reconhecem o papel do Museu de informar e preservar a história oficial e dão importância a isso.

Importante analisar também a relação sobre o que as pessoas destacam como sendo os elementos mais significativos da exposição e se elas se sentem representadas ou não. A grande maioria das pessoas que associou os elementos que falavam da figura de Tancredo Neves e sobre a democracia respondeu que se sentia representada, mas também, por esse mesmo motivo, a maioria disse que não se sentia representada. $O$ fato de a pessoa destacar que os elementos mais significativos da exposição eram relacionados à democracia e a Tancredo Neves nada tem a ver com o fato de ela se sentir representada ali ou não. Pode-se notar também que a relação com os heróis nacionais é mínima, tanto as pessoas que responderam sim quanto as que responderam não. 
Verônica Bemvenuto da Abreu e Silva, Ana Lúcia Abreu e Gomes Exposição de longa duração do panteão da pátria, Brasília: sua relação com o público (2015)

Tabela 1: Relação entre sentir-se representado pela exposição e elementos de destaque da exposição: Sendo brasileiro, você diria que se sente representado

\begin{tabular}{ccccccc}
\hline $\begin{array}{l}\text { Quais elementos essa exposição quer } \\
\text { destacar ao visitante? (Categorias) }\end{array}$ & Sim & Não & Não respondeu & $\begin{array}{c}\text { Não soube } \\
\text { responder }\end{array}$ & Total \\
\hline Tancredo Neves/Democracia & 115 & 37 & 6 & 12 & 170 \\
\hline Heróis Nacionais & 23 & 8 & 1 & 0 & 32 \\
\hline História do País & 40 & 4 & 1 & 1 & 46 \\
\hline Não respondeu & 10 & 3 & 16 & 1 & 30 \\
\hline Outros & 50 & 7 & 1 & 9 & 67 \\
\hline Total & 238 & 59 & 25 & 23 & 45
\end{tabular}

Fonte: Exposição de longa duração do panteão da pátria, Brasília

O fato das pessoas se sentirem identificadas naquele lugar por ele contar uma parte importante da história do país não significa que elas concordam com o discurso ambíguo que o Museu propõe. Ao se promover um discurso contra a ditadura dever-se-ia tomar o cuidado de não exaltar como heróis nacionais figuras ambíguas da história do país.

As pessoas que não se sentem ali representadas, não se identificam justamente com a principal mensagem que o Museu quer passar, elas não se sentem identificadas com os heróis nacionais ali presentes nem com o expresidente Tancredo Neves. Geralmente, quando mencionam o livro de aço dos heróis nacionais, é para ressaltar que não se identificam com os nomes inscritos no livro.

As impressões deixadas nos questionários ao perguntarmos qual era a opinião geral do visitante sobre aquele espaço foram bastante diversificadas. De modo geral, as pessoas gostaram do espaço apesar de falarem que ele deve ser mais bem aproveitado, que precise de mais acessibilidade e que seja feito algo quanto à ventilação do espaço urgentemente, visto que ele é todo fechado e não possui ar-condicionado, ventiladores ou mesmo dutos de circulação de ar, deixando o espaço quente, abafado e com um cheiro muito forte.

Observa-se de um modo geral, que a exposição não alcançou seu objetivo ao fazer referência aos ditos heróis nacionais do país, nem cumprir seu papel de agente de diálogo. Ao não debater certos conceitos trabalhados naquele espaço o Museu não deixa claro ao visitante sobre qual conceito de 
Verônica Bemvenuto da Abreu e Silva, Ana Lúcia Abreu e Gomes

Exposição de longa duração do panteão da pátria, Brasília: sua relação com o público (2015)

herói, liberdade e pátria estão sendo ali trabalhados, deixando espaço para que personagens controversos na história do país figurem lado a lado no espaço.

\section{CONSIDERAÇÕES FINAIS}

O PPTN possui um discurso baseado no pensamento de Gustavo Barroso, de nacionalismo e verdade única, a história que ele conta é cristalizada, não questiona nem promove diálogos com o visitante. É um lugar de criação de "grandes heróis" e de uma homogeneização do que se pode chamar de identidade brasileira.

Este Museu e sua exposição foram entendidos aqui sob o ponto de vista do documento/ monumento de Jacques Le Goff, ele é um produto datado, fruto da sociedade da época em que foi criado e, essa mesma sociedade sentiu a necessidade de um monumento como esse. Mas na atualidade, a demanda por esse tipo de construção já mudou, e esse Museu deve ser adaptado às necessidades de nossa sociedade atual.

Se a população ainda vê a necessidade de locais como o PPTN, devemos atentar a quem estamos homenageando nesses espaços e deixar claro que é um espaço, sobretudo de discussões e diálogos e não de informações dadas e cristalizadas. Mário Chagas fala da função que os museus têm na atualidade, argumentando sua múltipla função.

[...] Os museus modernos são espaços de memória, de esquecimento, de poder e resistência; são criações historicamente condicionadas. São instituições datadas e podem, por meio de suas práticas culturais, ser lidas e interpretadas como um objeto ou um documento. Quando um pesquisador ou um profissional de museus debruça-se sobre essas instituições, compreendendo-as como elementos típicos das sociedades modernas, pode visualizar em suas estruturas de atuação três aspectos distintos e complementares: do ponto de vista museográfico, a instituição museal é um campo discursivo; do ponto de vista museológico, é um centro produtor de interpretação; e, do ponto de vista histórico-social, é arena política. (CHAGAS, 2009, p. 60). 
O museu é entendido como campo discursivo, pois passa sempre uma mensagem. É também um centro produtor de interpretação porque, ao se comunicar com o visitante, produz significados que podem ser interpretados de várias maneiras. E, é também um espaço de arena política, pois essa mensagem sempre vai ter uma intenção definida, ressaltando algum discurso determinado, usando de seu poder de influência para evidenciar seu posicionamento. Nesta pesquisa, esses três aspectos são aplicados ao PPTN, que possui um discurso bem definido e é um lugar político, situado em um local de significados cívicos bem marcados e uma história de criação que diz muito sobre o que aquele espaço tem a intenção de expressar.

É sempre importante ter em mente que o objetivo principal de toda exposição é estabelecer um diálogo entre o visitante e o objeto (HERÁNDEZ. 2001). A mensagem que o objeto passa é mais importante que o objeto por si só. A intenção do presente trabalho foi saber qual a mensagem que, de um modo geral, o público do Museu capta ao visitar o espaço.

Foi identificado que a maioria das pessoas sai com uma impressão positiva do Museu, de que ele está cumprindo seu papel educador de informar, no caso, sobre uma parte da história do país. Mas a população sente ainda necessidade de ver elementos representativos da pluralidade da sociedade em que ela vive, e não a homogeneidade estática que o Museu apresenta.

Foi uma minoria dos entrevistados que relacionou aquele espaço aos nossos ditos heróis nacionais. Isso mostra o quão controverso e pouco significativo eles são na nossa atual sociedade.

Esta pesquisa contribuiu na área da museologia e dos estudos de públicos em museus visto que as instituições de Brasília ainda carecem desse tipo de pesquisa e aquele Museu em especial não possuía um estudo qualitativo sobre seu público. O retorno que foi dado por meio desta pesquisa foi de estabelecer uma comunicação com o público visitante, dando espaço para que as pessoas deixassem suas impressões sobre o espaço e sobre a história que ele conta e a oportunidade que o Museu tem de saber o que as pessoas pensam do espaço e como ele pode adaptar-se para construir um 
Verônica Bemvenuto da Abreu e Silva, Ana Lúcia Abreu e Gomes Exposição de longa duração do panteão da pátria, Brasília: sua relação com o público (2015)

conhecimento para e com a comunidade, não sentindo a necessidade de estar apartado dela.

\section{REFERÊNCIAS}

BALLAROTTI, C. A construção do mito de Tiradentes: de mártir republicano a herói cívico na atualidade. Revista Antíteses, v. 2, n. 3, p. 201-225, 2009.

BOURDIEU, P. A Força da representação. In: A Economia das trocas lingüísticas: o que falar quer dizer. São Paulo: Universidade de São Paulo, 1996. p. 107-116.

BOURDIEU, P. O amor pela arte: os museus de arte na Europa e seu público. São Paulo: EDUSP, 2007.

CARVALHO, J. M. Tiradentes: Um herói para a República In: A formação das almas: o imaginário da República no Brasil. São Paulo, Companhia das Letras, 1990, pp. 55-73.

CHAGAS, M.. A Imaginação museal: museu, memória e poder em Gustavo Barroso, Gilberto Freyre e Darcy Ribeiro. Rio de Janeiro. Minc/IBRAM. 2009.

DAVALLON, J. Introduction. Le public au centre de l'évolution du musée. In: Publics et Musées. n. 2, 1992. Regards sur l'évolution des musées (sous la direction de Jean Davallon). p. 10-18.

. Le musée est- il vraiment un média. In: Publics et musées. n. 2, 1992. Regards sur l'évolution des musées (sous la direction de Jean Davallon). p. 99123

- L'invention simultanée du visiteur et de l'exposition. In: Publics et Musées. N², 1992. Regards sur l'évolution des musées (sous la direction de Jean Davallon) p. 71-98.

FORTE. O uso de questionários em trabalhos científicos. 2007.

FUNARI, P.; CARVALHO. Museu e identidade nacional: reflexões e propostas. In: SEMANA NACIONAL DE MUSEUS, 9, 2011, Minas Gerais. Anais... UNIFAL, 2011. p. 9-22.

HALL, S. As culturas nacionais como comunidades imaginadas. Rio de Janeiro: DPEA, 2006.

HERNANDEZ, F. Manual de museologia. Madrid-Espanha, Sintesis. 2001. 

(2015)

KOPTCKE, L. S. CAZELLI, S. LIMA, J. M.. Os museus e seus visitantes: uma analise do perfil dos públicos dos museus do Rio de Janeiro e Niterói. In: ABREU, R.; CHAGAS, M. S.; SANTOS M. S. (Org.). Museus, coleções e patrimônios: narrativas polifônicas. Rio de Janeiro: IPHAN, 2007. 68 - 92.

KOPTCKE, L. PEREIRA, M. Museus e seus arquivos: em busca de fontes para estudar os públicos. Hist. cienc. saúde -Manguinhos [online]. 2010, vol.17, n.3, pp.809-828.

KÖPTCKE, L. S. Público, o $x$ da questão? A construção de uma agenda de pesquisa sobre os estudos de público no Brasil. Revista do Programa de PósGraduação em Ciências da Informação da Universidade de Brasília, v. 1, n. 1, p. 209-235, 2012. Disponível em:

<http://www.red.unb.br/index.php/museologia/article/view/6854/5522> Acesso em: 17 jun. 2015

- Observar a Experiência museal: uma prática dialógica? In: Cadernos Museu da Vida. Coordenação de Educação em Ciências do Museu da Vida. p. 5-22, 2003.

LE GOFF, J. História e memória. 4 ed. Campinas: Unicamp, 1996.

MATTA, R. Carnavais malandros e heróis: para uma sociologia do dilema brasileiro. Rio de Janeiro: Rocco, 1997.

MENESES, U. B. T. A problemática da identidade cultual nos museus: de objetivo (de ação) a objeto (de conhecimento). Anais do Museu Paulista: História e Cultura Material. São Paulo, v.1, n. 1. p. 207-222. 1993.

MUSEU DO PANTEÃO DA PATRIA. Centro cultural dos três poderes. Brasília, DF, [201].

SANTOS, M. C. T. M. O papel dos museus na construção de "uma identidade nacional". In: Anais do Museu Histórico Nacional. v. 28, Rio de Janeiro, n. 28, p. 21-36, 1996.

SANTOS, M. S. A escrita do passado em museus históricos. Granmond. Rio de Janeiro. 2006. p. 41- 54.

SENADO FEDERAL. Lei no 11.597, 29 de novembro de 2007. . Projeto de lei $\mathbf{n}^{\circ}$ 99, de 2005.

STUDART, D. Museus e famílias: percepções e comportamentos de crianças e seus familiares em exposições para o público infantil. História, Ciências, Saúde - Manguinhos, v. 12, 2005. 


\title{
Title
}

Long term exhibition of the pantheon, in brasília: Your relationship with the public (2015)

\begin{abstract}
Introduction: This work is a result of the public research conducted in September 2015 in the museum of Panteão da Patria, located in Praça dos Três Poderes, in Brasília, Distrito Federal. The museum has a well-defined speech and is considered a political place.
\end{abstract}

Objectives: The objective of this study was to analyze the relationship of the public with that space, to verify if people feel represented with the speech of the exhibition, to identify the processes that led to the construction of the space and to make an analysis of how the Museum's objectives are understood by the visitors.

Methodology: This study was classified as a reception study aimed to the spontaneous visitor of the exhibition. First, a contextualization of the history of the Pantheon was made, data were collected about the Museum and its collection in order to understand more thoroughly what motivated its creation and what discourse it wants to transmit to the visitor. In a second moment, through the application of questionnaires, it was made the identification of who was the visiting public of the museum and if the visitors identify or not with that space. The information collected was systematized in the SPSS program.

Results: It was identified that most of the interviewees came away with a positive impression of the museum for he spoke of the life of Tancredo Neves and emphasize a patriotic feeling, but it was a minority of the visitors that identified with the called national heroes that the museum presents. Visitors still miss the elements that are more representative of the plurality of society in space.

Conclusions: Although the population still feels the need for spaces such as the Pantheon, it should be made clear that the museum is a space for discussions and dialogues, not simply to present a crystallized and unquestioned history.

Keywords: Pantheon. Panteão da Pátria. Public studies. Representation.

\section{Titulo}

Exposición de larga duración del panteão de la patria, Brasilia: Su Relación con el Público (2015)

Introducción: Este trabajo es el resultado de la investigación de público realizada en septiembre de 2015 en el Museo del Panteón de la Patria, situado en la Plaza de los Tres Poderes, en Brasilia, Distrito Federal. El museo tiene un discurso bien definido y se considera un lugar político.

Objetivos: El objetivo de este estudio fue analizar la relación del público con ese espacio, verificar si las personas se sienten representadas con el discurso de la exposición, identificar los procesos que llevaron a la construcción del espacio y hacer un análisis de cómo los objetivos del Museo son comprendidos por los visitantes .

Metodología: Este estudio fue clasificado como un estudio de recepción dirigido al visitante espontáneo de la exposición. En primer lugar se hizo una contextualización de la historia del Panteón, se recogieron datos acerca del Museo y de su acervo a fin de comprender más a fondo lo que motivó su creación y qué discurso quiere transmitir al visitante. En un segundo momento, por medio de aplicación de cuestionarios fue 
Verônica Bemvenuto da Abreu e Silva, Ana Lúcia Abreu e Gomes

Exposição de longa duração do panteão da pátria, Brasília: sua relação com o público (2015)

hecha la identificación de cuál era el público visitante del museo y si los visitantes se identifican o no con aquel espacio. La información recopilada fue sistematizada en el programa SPSS.

Resultados: Se identificó que la mayoría de los entrevistados salió con una impresión positiva del museo por él hablar de la vida de Tancredo Neves y resaltar un sentimiento patriota, pero fue una minoría de los visitantes que se identificó con los llamados héroes nacionales que el museo presenta. Los visitantes todavía sienten falta de elementos más representativos de la pluralidad de la sociedad en el espacio.

Conclusiones: A pesar de que la población todavía siente necesidad de espacios como el Panteón, se debe dejar claro que el museo es un espacio para discusiones y diálogos, y no para simplemente presentar una historia cristalizada y sin cuestionamientos.

Palabras clave: Panteão de la Patria. Estudios de público. Representación.

Recebido: 10.03 .2017

Aceito: 10.11 .2017 